\title{
Development of the sea urchins Temnopleurus toreumaticus Leske, 1778 and Temnopleurus reevesii Gray, 1855 (Camarodonta: Temnopleuridae)
}

\author{
Chisato Kitazawa ${ }^{1 *}$, Chikara Sakaguchi ${ }^{1}$, Hajime Nishimura ${ }^{1}$, Chiaki Kobayashi ${ }^{1}$, Tomomi Baba ${ }^{1}$ and Akira Yamanaka ${ }^{2}$
}

\begin{abstract}
Background: Sea urchin larvae near metamorphosis form an adult rudiment that is a complex of the juvenile structures. However, the details of the mechanisms that form the adult rudiment are unknown. The temnopleurid sea urchins Temnopleurus toreumaticus and Temnopleurus reevesii occur in Japan, but the development of their juvenile morphology has not been described. In this study, we observed their development by light and scanning electron microscopy to follow the adult rudiment formation and to consider the mechanisms of evolution of juvenile morphology in sea urchins.
\end{abstract}

Results: The prism embryos of both species formed two primary pore canals that elongated from the left and right coelomic sacs; the left canal connected the presumptive water vascular system to the hydropore. These organs were formed bilaterally and symmetrically in T. toreumaticus and with left-right asymmetry in T. reevesii. The right canal of both species had degenerated by the four-armed larval stage. At the prism stage, about six cells from the left oral ectoderm located between the left post-oral arm and the oral lobe formed a cell mass. The cell mass grew in diameter stepwise in T. toreumaticus by cell migration and by the formation of an epithelial pouch during the four- to six-armed larval stages and more rapidly in $T$. reevesii by the formation of a thin epithelium during the six-armed larval stage. In both species, the adult rudiment was formed by attachment of the cell mass to the hydrocoel. The larvae of T. toreumaticus metamorphosed from a tiny hole on the left ectoderm between the post-oral and postero-dorsal arms.

Conclusions: These findings suggest that the developmental process involving the formation of two primary pore canals and a cell mass may have been acquired and conserved as common traits in the early development of indirect-developing temnopleurid species during evolutionary divergence from the Cidaroida.

Keywords: Temnopleurid sea urchins; Temnopleurus toreumaticus; T. reevesii; primary pore canal; cell mass; adult rudiment

\section{Background}

Sea urchins may display indirect development involving a planktotrophic pluteus larval stage or direct development in which the feeding pluteus larva is absent. Both modes of development have been studied for more than a century. In particular, indirect-developing species have been used for morphological and molecular analyses of early embryonic and larval development including fertilization, cleavage, gastrulation, and larval skeletogenesis. In contrast, phenomena that occur during later larval

\footnotetext{
* Correspondence: chisak@yamaguchi-u.ac.jp

${ }^{1}$ Biological Institute, Faculty of Education, Yamaguchi University, Yoshida 1677-1, Yamaguchi 753-8513, Japan

Full list of author information is available at the end of the article
}

development, which is concerned with appearance of juvenile morphology, have mainly been studied using direct-developing species; there have been few studies of these phenomena in indirect-developing species.

The most important morphogenetic event in the production of the juvenile morphology is the formation of the adult rudiment. The juvenile oral structures, including the primary podia, are formed within the adult rudiment, which consists of the hydrocoel and ectoderm on the larval left side (Okazaki 1975; MacBride 1914; Dan 1957). In the formation of the hydrocoel, the left coelomic sac, which develops from the tip of the archenteron at the prism stage, divides along the anterior-posterior axis into two parts, the anterior coelomic sac and the somatocoel. 
At the larval stage, this is followed by division of the left anterior coelomic sac along the anterior-posterior axis to form the axocoel and hydrocoel (Okazaki 1975; MacBride 1911, 1914, 1918). During this process, the left anterior coelomic sac forms the primary pore canal (PPC) and elongates to form the hydropore, which is an opening in the dorsal ectoderm that functions as a canal connecting the juvenile water vascular system and the madreporic pore for seawater exchange (Okazaki 1975; MacBride 1914; MacBride 1911, 1918). Recent studies have revealed that Temnopleurus hardwickii (Gray, 1855) and Mespilia globulus (Linnaeus, 1758), both of which belong to the Temnopleuridae (Camarodonta), form PPCs from both coelomic sacs at the prism stage, followed by degeneration of the right PPC (Hara et al. 2003; Kitazawa et al. 2012).

A number of variations have been reported in the process by which the adult rudiment is formed from the ectoderm (Emlet 2000; Figure 1). In the members of the most primitive order Cidaroida (Smith 1984; Kroh and Smith 2010), which includes Eucidaris thouarsii (L. Agassiz and Desor, 1846) (Emlet 1988), Phyllacanthus parvispinus (Tension Woods, 1878) (Parks et al. 1989), and Phyllacanthus imperialis (Lamarck, 1816) (Olson et al. 1993), the adult rudiment is formed directly on the left larval surface. In contrast, in other sea urchin species, an amniotic cavity (vestibule) forms as an autonomous invagination of the left larval ectoderm and forms the hydrocoel (Runström 1912, 1918; Czihak 1965, 1996). Recently, the larval developmental processes that give rise to the amniotic cavity in adult

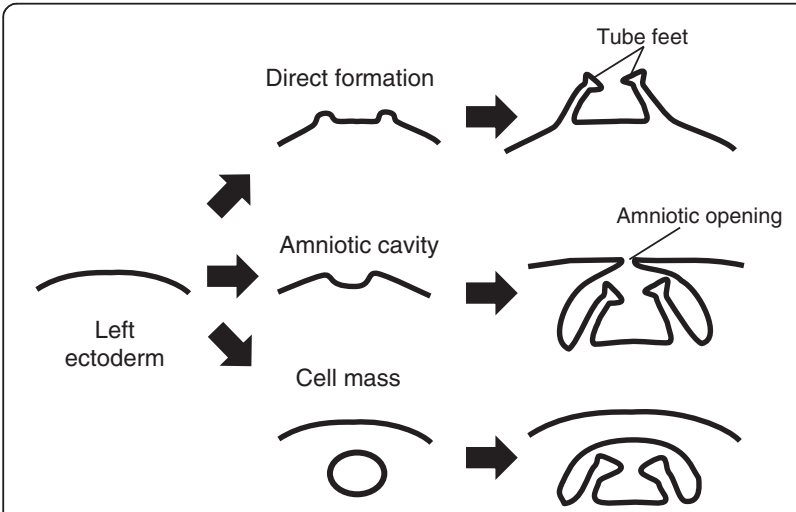

Figure 1 Variations of the ectodermal morphology of the adult rudiment of sea urchins larvae. The schematic diagrams show morphological changes of the ectoderm during adult rudiment formation. In members of the most primitive order, the Cidaroida, the larvae form tube feet directly on the left larval surface (top diagram; Emlet 1988; Parks et al. 1989; Olson et al. 1993). In contrast, in other sea urchin species, an invagination of the ectoderm forms an amniotic cavity that is always in contact with the exterior via an amniotic opening (middle diagram; Runström 1912, 1918; Czihak $1965,1996)$. In a few species belonging to the infraorder Temnopleuridea, the larva forms a cell mass and the adult rudiment develops internally from the epithelium derived from this cell mass (bottom diagram; Fukushi 1959, 1960; Mortensen 1921; Ubisch 1959). rudiment formation were described in the model sea urchin Strongylocentrotus purpuratus (Stimpson, 1857) to elucidate the genomic regulatory system underlying development (Smith et al. 2008). In contrast to this developmental pattern, a few species including T. hardwickii, M. globulus, and Genocidaris maculata (A. Agassiz, 1869) that belong to the infraorder Temnopleuridea (Camarodonta) form a cell mass (CM) during the early larval stage instead of an amniotic cavity (Fukushi 1959, 1960; Kitazawa et al. 2012; Mortensen 1921; Ubisch 1959). Also, a report on the development of another temnopleurid sea urchin Salmacis bicolor (L. Agassiz in L. Agassiz and Desor, 1846) referred to a similar organ as the amnion (Aiyar 1935). Therefore, it is important to further investigate the temnopleurid sea urchins to better understand the evolutionary changes leading to the formation of juvenile morphology.

Temnopleurus toreumaticus (Leske, 1778) and Temnopleurus reevesii (Gray, 1855) are temnopleurid sea urchins that inhabit Japanese waters (Nishimura 1995; Shigei 1986: Kitazawa et al. 2007). Although there are data on the development of $T$. toreumaticus up to the six-armed pluteus stage (Mortensen 1921; Onoda, 1936; Okada and Miyauchi 1958; Takata and Kominami 2004; Kitazawa et al. 2010), there has been no report on the formation of the juvenile morphology of this species. The development of $T$. reevesii has never been reported.

In this study, we describe the development of $T$. toreumaticus and $T$. reevesii, particularly with respect to the formation of the juvenile morphology, and we discuss these mechanisms in relation to sea urchin evolution.

\section{Methods}

\section{Fertilization and culturing of specimens}

Adult T. toreumaticus and T. reevesii sea urchins were collected from the Inland Sea (Setonai), Yamaguchi Prefecture, Japan. To induce spawning, $0.5 \mathrm{M} \mathrm{KCl}$ solution was injected into the body cavities of the $T$. toreumaticus and $T$. reevesii specimens between July and January. The resulting eggs were washed several times with filtered seawater (FSW). The eggs were then fertilized in FSW and cultured in plastic dishes containing artificial sea water (ASW, TetraMarin ${ }^{\oplus}$ Salt Pro, Tetra, Melle, Germany) at $24^{\circ} \mathrm{C}$ until the four-armed pluteus larval stage.

The larvae were cultured according to previously described methods with some modifications (Kitazawa et al. 2012; Wray et al. 2004). Approximately, 50 fourarmed pluteus larvae were transferred to $50-\mathrm{ml}$ plastic tubes filled with ASW plus a few drops of ASW containing Chaetoceros gracilis as the larval food.

Each plastic tube contained a small air bubble to stir the seawater. The culture tubes were shaken horizontally in a plastic tray fixed to a double shaker (NR-3, TAITEC, Saitama, Japan) at rate of $0.71 \mathrm{~min}^{-1}$. The culture seawater in the tubes was replaced with fresh ASW containing food 
every 3 days under a stereomicroscope (SZ61, Olympus, Tokyo, Japan; SMZ1500, Nikon, Tokyo, Japan). Metamorphosing larvae were transferred to a plastic dish filled with ASW and fed a piece of seashell coated with algae. When the juveniles had grown to approximately 2 to $3 \mathrm{~mm}$ in diameter, they were transferred to a small aquarium.

\section{Light microscopy of specimens}

Specimens at each stage were observed and photographed under a microscope (Optiphot-2, Nikon) or a stereomicroscope using digital camera ( $\mu 810$, DP72-SETA, Olympus, DS-Fil, Nikon). The diameter of the cell mass and the larval body length were measured using a micrometer.

\section{DAPI staining to count cell number in the cell mass}

T. toreumaticus living larvae were incubated in ASW containing $0.3 \mathrm{mM}$ 4', 6-diamidino-2-phenylindoledihydrochloride (DAPI) for approximately 10 to $20 \mathrm{~min}$ in the dark. They were then observed and photographed under a fluorescence microscope (E2-FL, ECLIPSE E200, Nikon) using a digital camera (DS-Fil, Nikon).

\section{Scanning electron microscopy of embryos and larvae}

T. toreumaticus embryos and larvae were fixed with $1 \%$ osmium tetroxide in $0.6 \mathrm{M}$ sucrose and $0.05 \mathrm{M}$ sodiumcacodylate buffer $(\mathrm{pH} 7.4)$ for $1 \mathrm{~h}$ on ice or with $4 \%$ formaldehyde in ASW for approximately $1 \mathrm{~h}$ at room temperature as previously described (Kitazawa et al. 2012). The fixed specimens were dehydrated in graded ethanol dilutions and gradually transferred to 2-methyl-2-propanol (ethanol, 2-methyl-2-propanol ratios of 3:1, 1:1, and 1:3). After washing twice with 2-methyl-2-propanol, the specimens were freeze-dried (model BFD-21S, Vacuum Device Inc., Ibaraki, Japan). The dried specimens were mounted on an aluminum stage using double-sided conductive aluminum tape and then coated with gold using a fine ion sputter (E-1010, Hitachi High-Technologies, Tokyo, Japan). They were then observed and photographed under the scanning electron microscope (Miniscope TM-1000S, Hitachi High-Technologies).

\section{Results}

\section{Development of $T$. toreumaticus after the blastula stage}

Morphogenesis of $T$. toreumaticus embryos after the blastula stage was observed by microscopy. In most embryos, primary mesenchyme cells (PMCs) entered the blastocoel $10 \mathrm{~h}$ after fertilization and gastrulation started approximately $1 \mathrm{~h}$ later at $24^{\circ} \mathrm{C}$. After gastrulation, a pair of coelomic sacs was formed on the tip of the archenteron. Approximately $23 \mathrm{~h}$ after fertilization, a PPC extended from each coelomic sac towards the lateral dorsal surface. This was observed in more than $80 \%$ of prism embryos in experiments using multiple clutches from different mothers (Figure 2A). The PPCs remained bilateral until the two-armed larval stage (Figure 2B,E). The prism larvae formed a CM by invagination of a few cells on the oral ectoderm between the left post-oral arm and the oral lobe $26 \mathrm{~h}$ after fertilization. This was observed in a single larva (3.7\%) of 27 with a CM, with pinching-off occurring $34 \mathrm{~h}$ after fertilization (observed in 100\% of larvae with a CM, $n=27$; Figure $2 \mathrm{C}, \mathrm{D}, \mathrm{E})$. In the four-armed larvae, approximately 2 days after fertilization, the CM was composed of $5.5 \pm 0.2$ cells (mean value \pm standard error, $n=15$, larvae from multiple clutches from different mothers; Figure 3A). By this stage, the right PPC had degenerated (Figure 2F).

The CM gradually increased in diameter with the growth of the larval body until the six-armed larval stage (Figures 2G,H,I,J,K,L and 3). The CM then became a hollow pouch as the diameter grew by migration of cells comprising the $\mathrm{CM}$ (Figures $2 \mathrm{G}, \mathrm{H}$ and $3 \mathrm{~B}$ ). However, the mean number of cells constructing the CM did not change during the four-armed larval stage ( $5.5 \pm 0.2, n=15,2$ days after fertilization; $6.0 \pm 0.2, n=11,7$ days after fertilization; Figure 3A,B). The size of the larva and diameter of the $\mathrm{CM}$ remained constant during the four-armed stage, but the CM grew again after a few days when the larva reached to the six-armed stage (Figure $3 \mathrm{E}$ ). The hydrocoel that was formed by division of the left coelomic sac also increased in size and approached the CM (Figure 2H,I). Approximately 20 days after fertilization, at the six-armed larval stage, the CM became attached to and covered the hydrocoel (Figure 2I,J); this complex of tissues formed the adult rudiment (Figure $2 \mathrm{~K}$ ). At the same time, the most anterior tip of the CM started to bud towards the ectoderm (Figure 2J,K) and the projection became detached from the CM (Figure 2L). This structure corresponds the 'small process' observed in the larvae of $T$. hardwickii (Fukushi 1960) and M. globulus (Kitazawa et al. 2012). Around this stage, patches of yellowish-green cells previously described in M. globulus, but not in T. toreumaticus (Onoda 1936), were present on the larval post-oral and postero-dorsal rods, but not on other rods (Figure 2L). The adult rudiment was then formed and also one pair of pre-oral arms (Figure 4A). Primary podia developed internally until metamorphosis (Figure 4B,C,D,E). A small process appeared adjacent to the larval ectoderm (Figure 4B') and then changed its shape (Figure 4D'). At this stage, the larvae formed a pedicellaria on the posterior end (Figure 4A,B) and then finally formed three pedicellariae on the posterior end and a pedicellaria on the right ventral side (Figure 4C).

Approximately 30 days after fertilization, a small hole appeared in the left oral ectoderm between the post-oral and postero-dorsal arms of the eight-armed larvae (Figure 4E). After a few days, the ectodermal hole became bigger and juvenile spines and tube feet were identified (Figure 4F) 

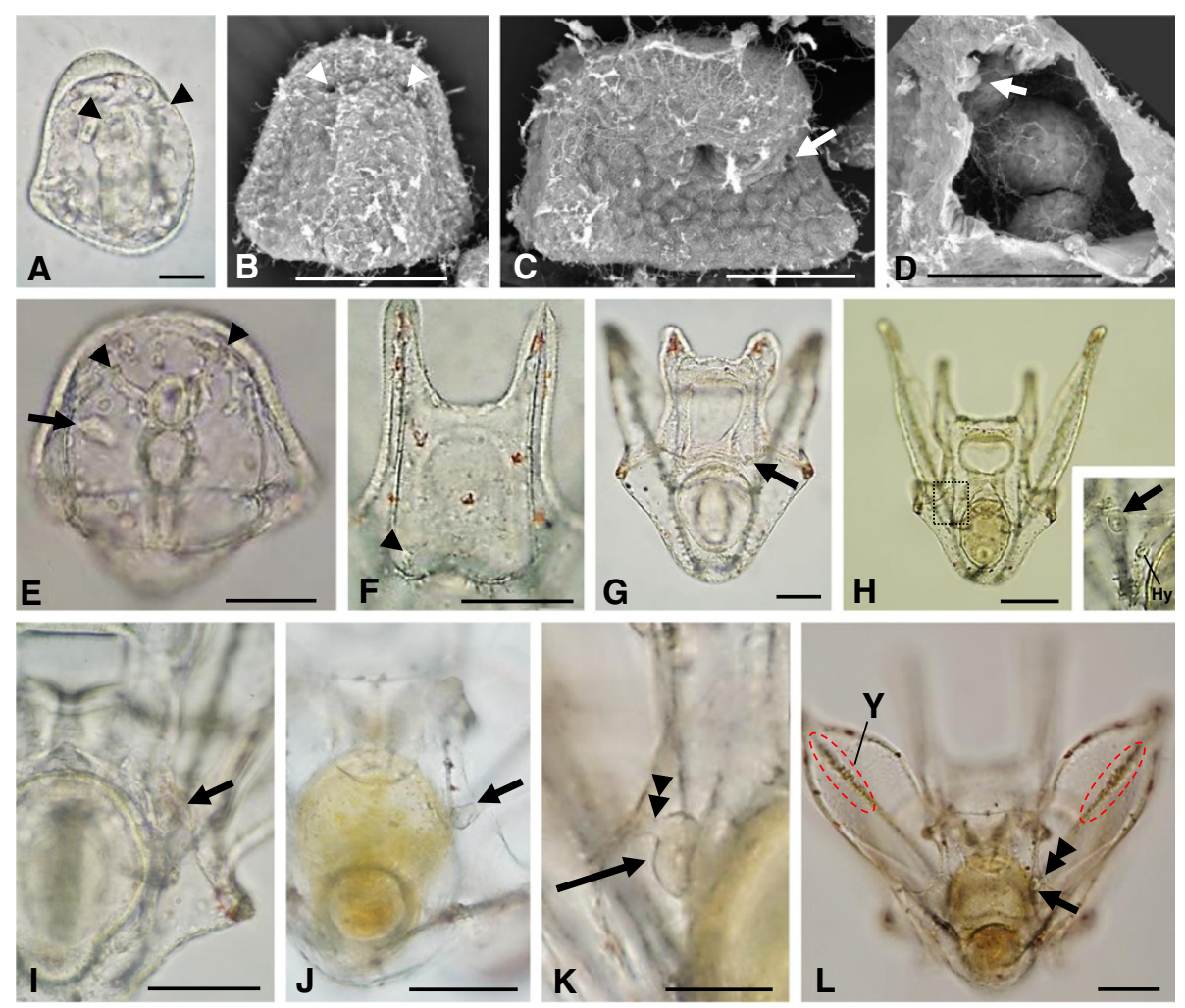

Figure 2 Development of Temnopleurus toreumaticus from the prism to the six-armed larval stage. Light (A,E to $L)$ and scanning electron micrographs ( $\mathbf{B}$ to $\mathbf{D}$ ) showing the initial left-right asymmetry of the elongation of the primary pore canal (PPC) and the initiation of the adult rudiment formation from the cell mass (CM). (A,B) Prisms $23 \mathrm{~h}$ after fertilization (dorsal view). The PPCs have formed bilaterally; the hydropores (arrowheads) are located bilaterally. (C,D) Prisms $26 \mathrm{~h}$ after fertilization: oral $\mathbf{( C )}$ and left lateral ( $\mathbf{D}$, the left lateral ectoderm was removed by cellophane tape before coating) views. Two cells have started to invaginate (arrow). (E) A two-armed larva with the CM $34 \mathrm{~h}$ after fertilization (aboral view). (F) A four-armed larva with a hydropore only on the left dorsal side 3 days after fertilization (dorsal view) (G) A four-armed larva 6 days after fertilization (ventral view). (H) A six-armed larva 10 days after fertilization (dorsal view). The insert shows higher magnification image in a black broken square. (I) A six-armed larva 15 days after fertilization (ventral view). The CM has attached to the hydrocoel. (J,K) Six-armed larvae 20 days after fertilization: ventral (J) and dorsal (K) views. The CM has budded a small process (double arrowheads). (L) A six-armed larva with a small process 22 days after fertilization (ventral view). Hy, hydrocoel; Y, yellowish-green cells (a red broken circle). Scale bar $=50 \mu \mathrm{m}$ for (A to D,F,K), $100 \mu \mathrm{m}$ for $(\mathbf{E}, \mathbf{G}$ to J,L).

and the larvae then metamorphosed. The time course of development after the blastula stage of this species is shown in Table 1. After metamorphosis, the juveniles (Figure 4G) grew into young adult sea urchins (Figure $4 \mathrm{H}$ ), which matured in approximately 2 years.

\section{Development of $T$. reevesii after the blastula stage}

The morphogenesis of $T$. reevesii after the blastula stage was also observed by microscopy. Ingression of PMCs into the blastocoel commenced approximately $9 \mathrm{~h}$ after fertilization (Figure 5A). The vegetal plate became thicker and gastrulation commenced $12 \mathrm{~h}$ after fertilization (Figure 5B). At $15 \mathrm{~h}$, ingression of secondary mesenchyme cells from the tip of the archenteron into the blastocoel was observed (Figure 5C). Then, the left and right coelomic sacs were formed by elongation of the tip of the archenteron $17 \mathrm{~h}$ after fertilization (Figure 5D). At this stage, the embryos began to form spicules bilaterally by aggregation of PMCs on the vegetal side. Approximately $20 \mathrm{~h}$ after fertilization, the archenteron curved towards the presumptive oral ectodermal region and its tip became attached. At this time, the left and right coelomic sacs extended projections towards the dorsal ectoderm asymmetrically along the embryonic body axis as PPCs (Figure 5E). The left PPC became elongated laterally to the left side, whereas the right PPC was elongated towards the right dorsal surface. However, the left hydropore, which is the opening of the left PPC on the ectoderm, gradually migrated more dorsally. Thus, both PPCs appeared to elongate symmetrically (Figure 5F). The embryos also started to form fenestrated spicules, which are presumptive post-oral rods, and the larval mouth opened $21 \mathrm{~h}$ after fertilization. During this period, both PPCs remained symmetrical ( $100 \%$ symmetrical at $23.5 \mathrm{~h}, n=44$; at $24.5 \mathrm{~h}, n=36$; at $26.5 \mathrm{~h}, n=23$; and at $29.5 \mathrm{~h}, n=16$ after fertilization). The left ectoderm located between the presumptive post-oral 


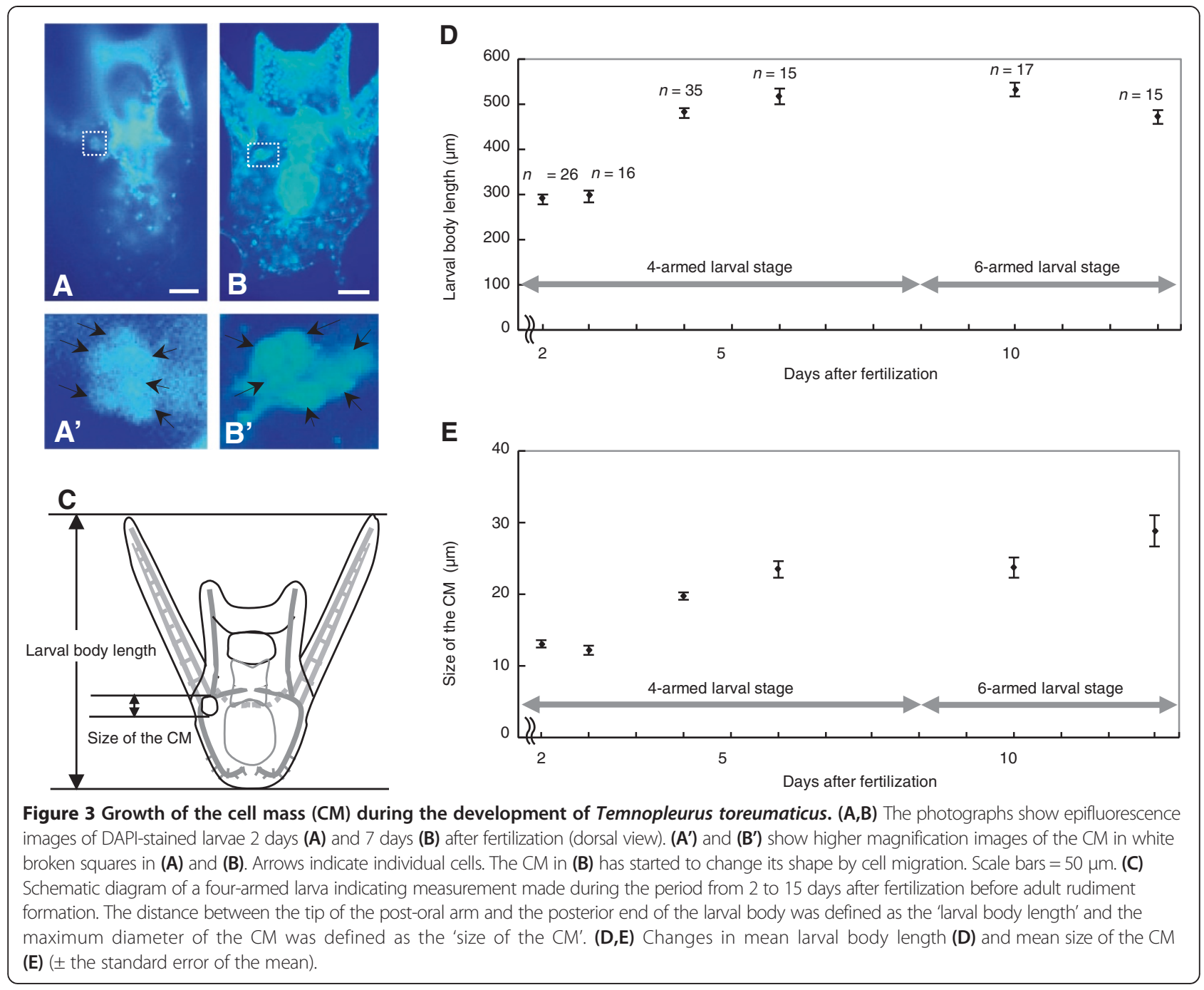

arm, and the oral lobe began to invaginate to form the CM $24.5 \mathrm{~h}$ after fertilization (observed in one larva of 21 with the $\mathrm{CM}$ ). In the period up to about $26 \mathrm{~h}$ after fertilization, the CM was completely pinched off into the body $(92.0 \%$ at $26.5 \mathrm{~h}, n=25 ; 100 \%$ at $29.5 \mathrm{~h}, n=16$; Figure 5G,H). Thereafter, the larvae elongated their postoral arms and developed into two-armed pluteus larvae approximately $30 \mathrm{~h}$ after fertilization, following which the right PPC started to degenerate from the ectodermal end (Figure $5 \mathrm{H})$, and finally disappeared $(96.1 \%$ had only a left PPC 2 days after fertilization, $n=51$; Figure 5I,J,K). The four-armed larvae formed fenestrated post-oral rods and single antero-lateral rods (Figure $5 \mathrm{~L}$ ). When the larvae started to form postero-dorsal arms approximately 9 days after fertilization, the $\mathrm{CM}$ grew and became attached to the hydrocoel (Figure 6A, $\mathrm{A}^{\prime}$ ); it then enlarged into a pouch with a thin wall (Figure 6B,B'). At this stage, the larvae also formed a pedicellaria on the posterior end (Figure $6 \mathrm{C}$ ) and second one at a later developmental stage. The enlarged $\mathrm{CM}$ changed from a thin pouch to a thick pouch
(Figure 6D,D'), and the complex of the CM and hydrocoel started to form the adult rudiment approximately 16 days after fertilization (Figure 6E,E'). At this stage, the larvae had a few yellowish-green cells on the post-oral (Figure 6E") and postero-dorsal rods but not on the antero-lateral (Figure 6E"') or pre-oral rods. At the eightarmed pluteus larval stage, the adult rudiment developed under the sheet of the $\mathrm{CM}$ to form primary podia (Figure 6F,F'), and a small process was identified on the anterior region of the adult rudiment (Figure 6F"). After about 30 days, the fully developed larvae metamorphosed to juveniles (Figure 6G,H), which grew into young mature sea urchins about $2.5 \mathrm{~cm}$ in diameter after approximately 1.5 years (Figure 6I). Table 1 shows the time course of the complete development of $T$. reevesii.

\section{Discussion}

The present study is the first to document the development of $T$. toreumaticus and $T$. reevesii up to metamorphosis. Both species first formed PPCs on both sides 

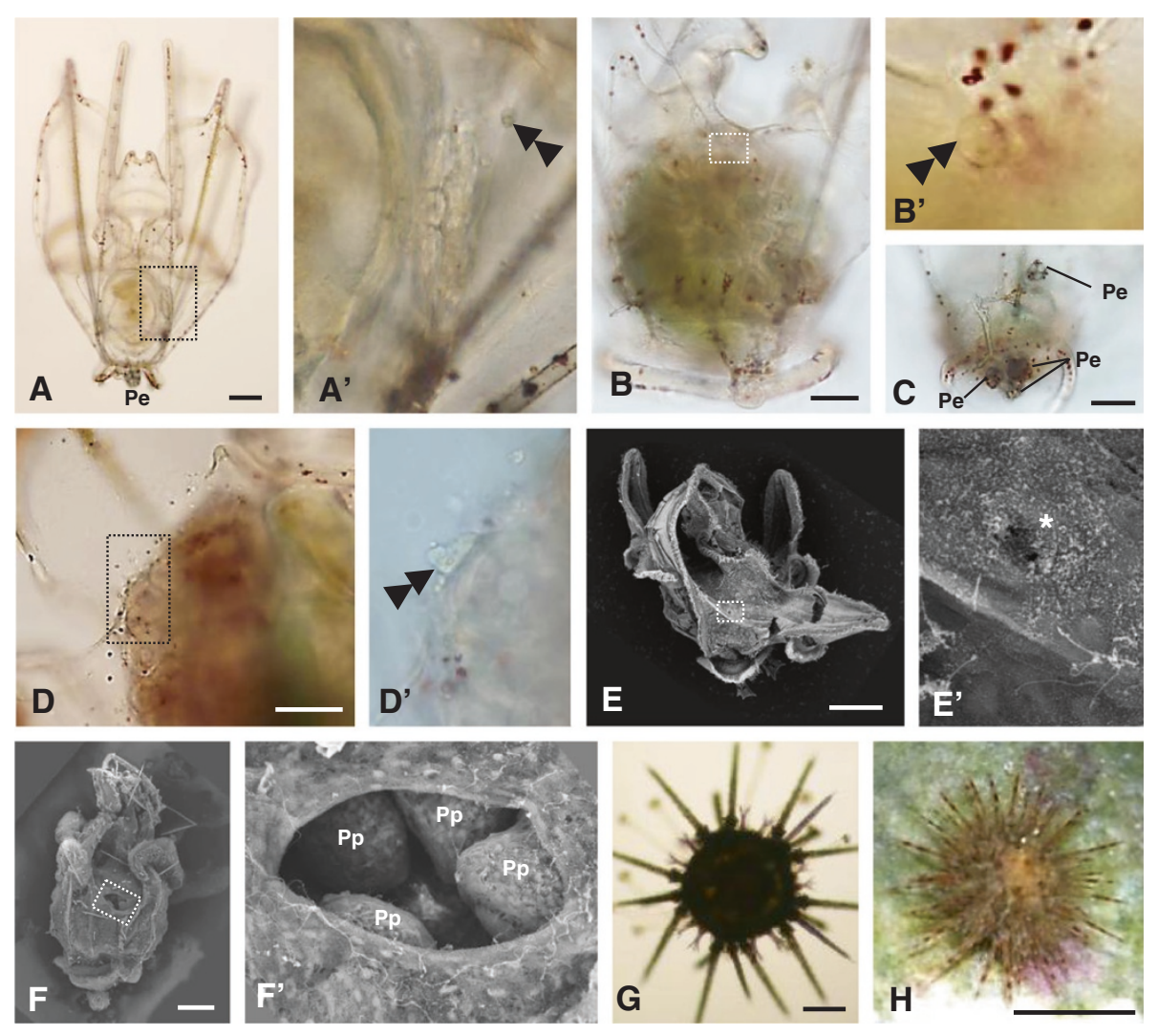

Figure 4 Morphogenesis of Temnopleurus toreumaticus from small process detachment to metamorphosis. Light $(A$ to $D, G, H)$ and scanning electron micrographs $(\mathbf{E}, \mathbf{F})$. ( $\left.\mathbf{A}^{\prime}, \mathbf{B}^{\prime}, \mathbf{D}^{\prime}, \mathbf{E}^{\prime}, \mathbf{F}^{\prime}\right)$ show higher magnification images in black $(\mathbf{A}, \mathbf{D})$ or white broken squares $(\mathbf{B}, \mathbf{E}, \mathbf{F})$. (A) An eight-armed larva 25 days after fertilization (ventral view). The larva has formed a pedicellaria on the posterior end. A small process (double arrowheads) is visible near the ectoderm in $\left(\mathbf{A}^{\prime}\right)$. $(\mathbf{B}, \mathbf{C})$ Eight-armed larvae with primary podia 30 days after fertilization: left lateral $(\mathbf{B})$ and posterior (C) views. When the area on the most anterior primary podium was focused on the ectodermal side (white broken square), a small process was identified. The larva has formed three pedicellariae on the dorsal end and a pedicellaria on the right ventral side. (D,E) Eight-armed larvae 31 days after fertilization: dorsal (D) and left lateral (E) views. The area between the left ectoderm and the adult rudiment has become narrow, and a very small hole is present on the left ectoderm between the left post-oral and postero-dorsal arms (asterisk). (F) An eight-armed larva 33 days after fertilization (left lateral view). Tube feet protrude from the opening in the ectoderm (F'). (G) A juvenile 35 days after fertilization (dorsal view). (H) A young adult sea urchin approximately 1.3 years after fertilization (dorsal view). Pe, pedicellaria; Pp, primary podium. Scale bar $=50 \mu \mathrm{m}$ for $(\mathbf{G})$ $100 \mu \mathrm{m}$ for (A to $\mathbf{F}$ ), and $5 \mathrm{~mm}$ for $(\mathbf{H})$

during early development; after which, the right PPC degenerated. In addition, both species formed a CM for adult rudiment formation, as observed in other indirectdeveloping temnopleurid species, including T. hardwickii (Hara et al. 2003) and M. globulus (Kitazawa et al. 2012), with some variation in the timing of the formation of each organ (Table 1).

The PPC is the earliest juvenile morphological trait, and in the embryos of both $T$. toreumaticus and $T$. reevesii, PPCs were formed on both left and right sides at the prism stage, but then the right PPC then degenerated during development to four-armed pluteus stage. This phenomenon has also been observed in T. hardwickii and M. globulus (Hara et al. 2003; Kitazawa et al. 2012) but has not been observed in indirect-developing species of the infraorder Temnopleuridea, such as $G$. maculata (Trigonocidaridae) (Ubisch, 1959), or in the direct-developing temnopleurid species, Holopneustes purpurascens (Agassiz, 1872) (Morris 1995). These results indicate that early bilateral PPC formation may be a feature common to indirect-developing temnopleurid sea urchins. Further detailed observations could determine whether bilateral early PPC formation is a feature common to all Temnopleuridea.

Despite the differences in the type of PPC formation both sides in T. toreumaticus, T. reevesii (Figures 2 and 5), T. hardwickii, and M. globulus (Hara et al. 2003; Kitazawa et al. 2012) and left side only in Hemicentrotus pulcherrimus (A. Agassiz, 1863) (Kitazawa et al. 2012), the formation of the PPC(s) is initiated during the late gastrula to prism stages. Recently, Bessodes et al. (2012) reported that asymmetrical TGF $\beta$ nodal expression along the left-right axis starts from the mid-gastrula stage at precursors of the right coelomic sac on the right side of the archenteron in 
Table 1 Development times of Temnopleurus toreumaticus and $T$. reevesii at $24^{\circ} \mathrm{C}$

\begin{tabular}{lcc}
\hline Developmental stages & \multicolumn{2}{c}{ Time after fertilization $^{\text {a }}$} \\
\cline { 2 - 3 } & T. toreumaticus & T. reevesii \\
\hline PMC ingression & $10 \mathrm{~h}$ & $9 \mathrm{~h}$ \\
Early gastrula stage & $11 \mathrm{~h}$ & $12 \mathrm{~h}$ \\
Prism stage & $16 \mathrm{~h}$ & $21 \mathrm{~h}$ \\
PPC formation & $23 \mathrm{~h}$ & $20 \mathrm{~h}$ \\
Initiation of CM formation & $26 \mathrm{~h}$ & $24.5 \mathrm{~h}$ \\
Two-armed pluteus stage & $28 \mathrm{~h}$ & $30 \mathrm{~h}$ \\
Four-armed pluteus stage & 2 days & 2 days \\
Six-armed pluteus stage & 10 days & 9 days \\
Adult rudiment formation & 21 days & 16 days \\
Eight-armed pluteus stage & 25 days & 26 days \\
Metamorphosis & 31 days & 33 days \\
\hline
\end{tabular}

We defined each developmental stage as a stage observed in more than $80 \%$ of 50 specimens. After the six-armed pluteus stage, the values show the developmental time of more than $50 \%$ of the surviving specimens.
Paracentrotus lividus (Lamarck, 1816). In the reports of Runström (1918) and Giudice (1986), the embryos of $P$. lividus appear to form only a single PPC. It was also reported that nodal signaling blocks the formation of the PPC by repressing bone morphogenetic protein (BMP) signaling in S. purpuratus, a species that also forms a single PPC on the left side (Luo and Su 2012). Therefore, it is important to analyze the timing of asymmetrically expressed genes, including nodal and BMP in T. toreumaticus and T. reevesii because it is possible that modification of their expression directs the formation of PPCs on the two sides and subsequent degeneration of the right.

PPCs first formed symmetrically on the left and right sides in T. toreumaticus (Figure 2A,B,E), whereas they formed asymmetrically in $T$. reevesii (Figure $5 \mathrm{E}, \mathrm{F}$ ), as summarized in Figure 7A. Previous reports have shown that symmetrical PPC formation is required for maintenance of normal larval body width in $T$. hardwickii (Hara et al. 2003). In contrast, asymmetrical formation of PPCs has been reported for M. globulus; the left PPC migrates from the left lateral to the left dorsal side and is independent of the maintenance of the larval body
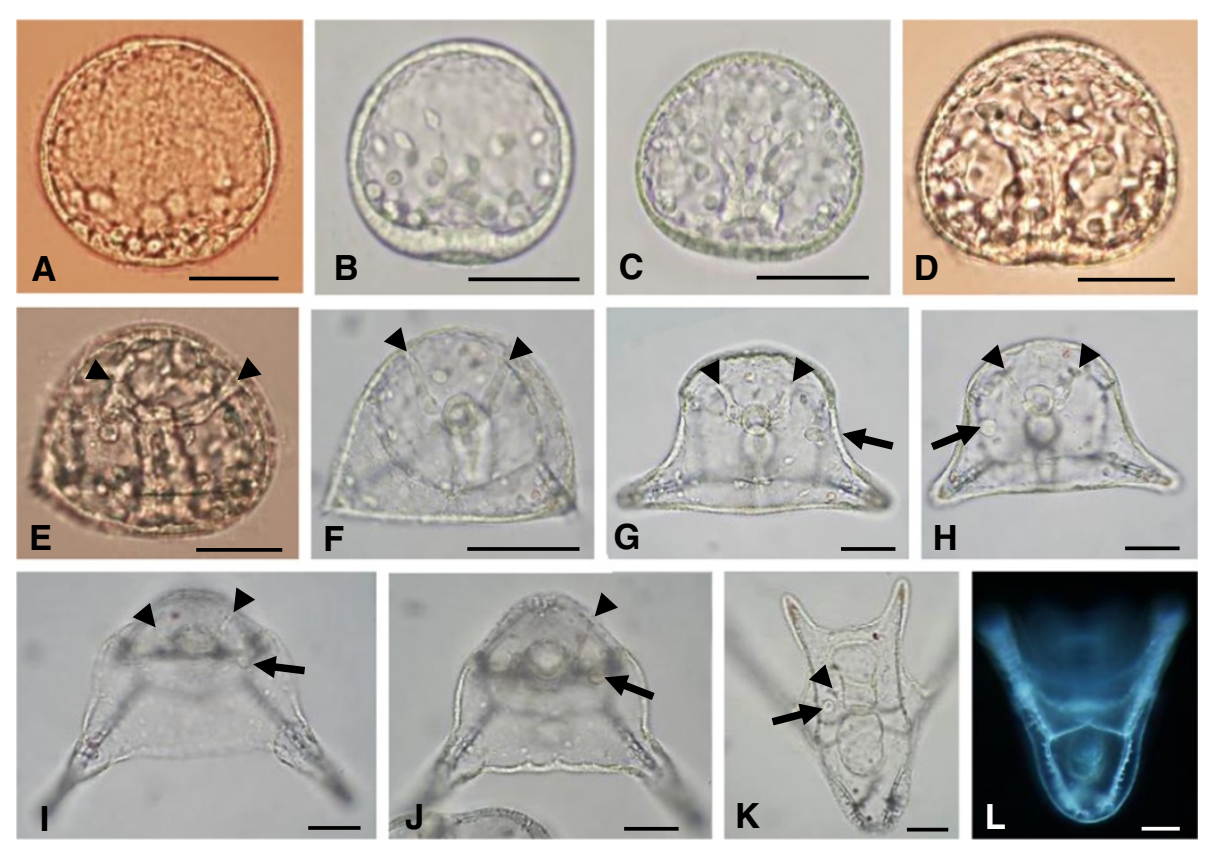

Figure 5 Early development of Temnopleurus reevesii from primary mesenchyme cell ingression to cell mass formation. Micrographs show the initial left-right asymmetry of the primary pore canal (PPC) elongation and the initiation of adult rudiment formation from the cell mass (CM). (A) A blastula $9 \mathrm{~h}$ after fertilization (lateral view). (B) An early-gastrula $12 \mathrm{~h}$ after fertilization (lateral view). (C) A mid-gastrula $15 \mathrm{~h}$ after fertilization (lateral view). (D) A late-gastrula with a pair of coelomic sacs $18 \mathrm{~h}$ after fertilization (lateral view). (E) A late-gastrula $20 \mathrm{~h}$ after fertilization (presumptive oral view). A PPC is elongated asymmetrically towards the ectoderm from each coelomic sac (arrowheads show hydropores): the left PPC elongated to the left lateral side and the right PPC elongated more dorsally. (F) A prism embryo $20 \mathrm{~h}$ after fertilization (oral view). PPCs are symmetrically elongated towards the ectoderm. (G,H) Two-armed larvae 27 h after fertilization: oral (G) and aboral $\mathbf{( H )}$ views. A part of the ectoderm between the left post-oral arm and the left oral lobe has started to invaginate (G, arrow) and then pinched off ( $\mathbf{H}$, arrow). (I,J) Two-armed larvae with a CM $30.6 \mathrm{~h}$ after fertilization (oral view). The right PPC has started to degenerate (I) and then disappeared (J). (K,L) Four-armed larvae 4 days after fertilization: dorsal (K) and ventral (L) views. Only the left PPC is visible (K). The body rods possess barbs and the post-oral rods are fenestrated (L). Scale bars $=50 \mu \mathrm{m}$. 

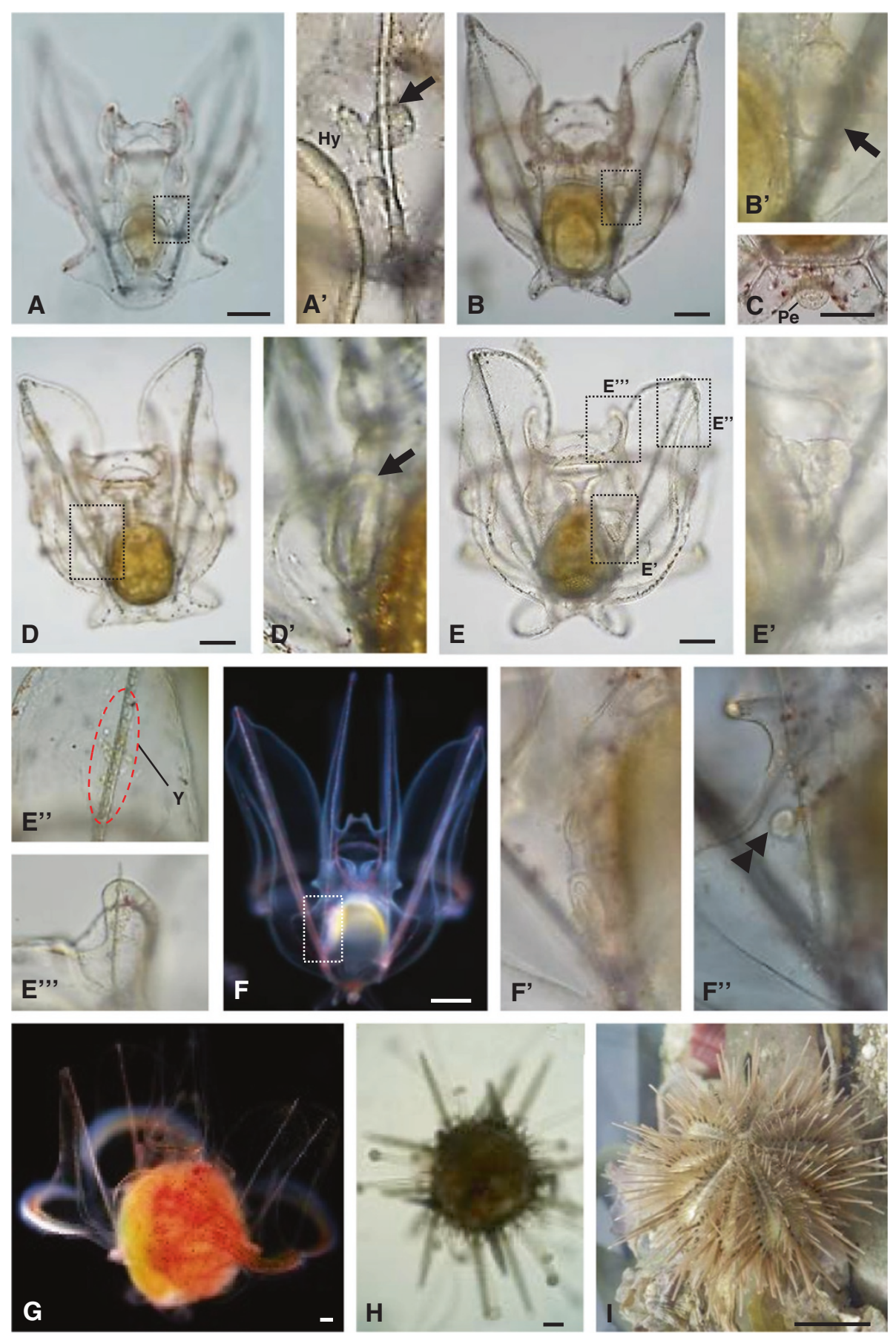

Figure 6 Morphogenesis of Temnopleurus reevesii after cell mass formation through to metamorphosis. $\left(A^{\prime}, B^{\prime}, D^{\prime}, E^{\prime}, E^{\prime \prime}, E^{\prime \prime \prime}, F^{\prime}, F^{\prime \prime}\right)$ show higher magnification images in black and white broken squares (A,B,D to F). (A,B) Six-armed larvae 9 days (A) and 11 days (B) after fertilization (ventral view). The cell mass (CM; arrow) has grown and has become attached to the hydrocoel (A). It has changed shape from a $C M\left(\mathbf{A}^{\prime}\right)$ to a thin pouch (B'). (C) A posterior pedicellaria of a six-armed larva 11 days after fertilization. (D,E) Six-armed larvae 16 days (D) and 17 days (E) after fertilization: dorsal (D) and ventral (E) views. The epithelium of the $C M$ has thickened $\left(\mathbf{D}^{\prime}\right)$ ), the $C M$ has covered the hydrocoel and the complex has started to form primary podia ( $\left.\mathbf{E}^{\prime}\right)$. Yellowish-green cells become visible in the post-oral ( $\left.\mathbf{E}^{\prime \prime}\right)$ and postero-dorsal arms ( $\mathbf{Y}$, a red broken circle) but not in the antero-lateral (E"') and pre-oral arms. $(\mathbf{F}, \mathbf{G})$ Eight-armed larvae 23 days $\mathbf{( F )}$ and 27 days $(\mathbf{G})$ after fertilization: dorsal $(\mathbf{F})$ and ventral (G) views. Primary podia are visible, although they are still covered with a thin sheet of the $C M\left(\mathbf{F}^{\prime}\right)$. A small process has formed $\left(\mathbf{F}^{\prime \prime}\right.$; double arrowheads). Thereafter, the larvae fully developed the adult rudiment (G). (H) A juvenile 31 days after fertilization (dorsal view). (I) A young sea urchin approximately 1.5 years after fertilization (dorsal view). Hy, hydrocoel. Pe, pedicellaria. Scale bars $=100 \mu \mathrm{m}$ for $(\mathbf{A}$ to $\mathbf{H})$ and $1 \mathrm{~cm}$ for (I). 


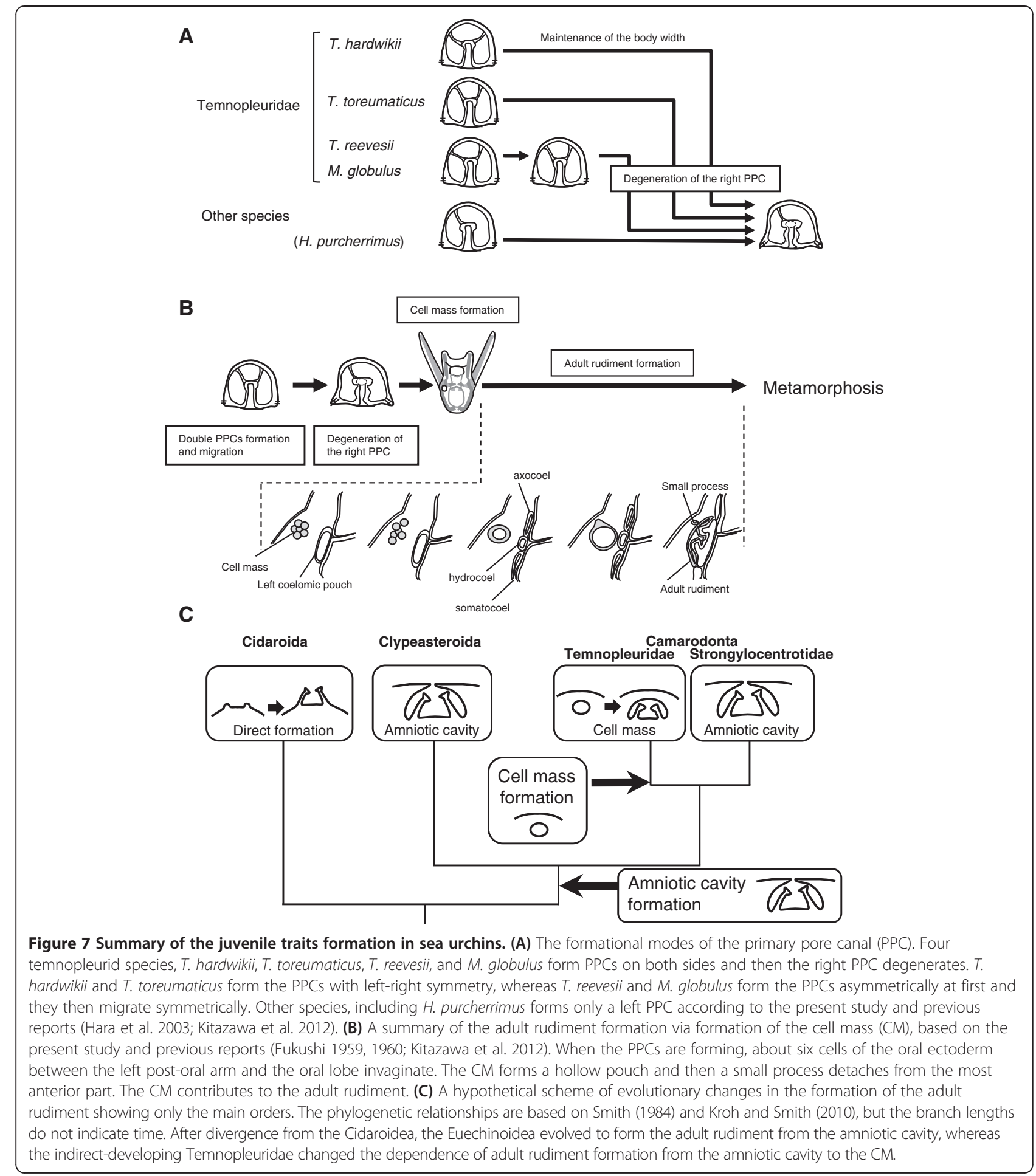

width (Kitazawa et al. 2012). In T. toreumaticus, the embryonic body cavity was very narrow and was enclosed by a thick epithelium (Figure 2A); the shape of epithelium at the blastula stage was changeable so that the wrinkled blastulae were formed (Kitazawa et al. 2009, 2010) and the PPCs formed symmetrically, perhaps for maintenance of the larval body width. In contrast, in $T$. reevesii embryos, the left PPC formed as a lateral elongation of the left coelomic sac to the left side and the right PPC was elongated dorsally from the right coelomic sac, followed by migration of the left hydropore dorsally (Figure 5). The body cavities of these larvae 
were not narrow and were enclosed by a thin epithelium (Figure 5) without the formation of the wrinkled blastula (Kitazawa et al. 2010). Therefore, PPC formation in $T$. toreumaticus may also contribute to the maintenance of normal body width as in T. hardwickii (Hara et al. 2003) but this may not be the case for $T$. reevesii. To clarify the early roles of PPCs in these species, future experiments involving the removal of PPCs may be necessary.

The present study indicates that $T$. toreumaticus and T. reevesii exhibit a type of development in which a $\mathrm{CM}$ gives rise to the adult rudiment, as has been previously observed in T. hardwickii (Fukushi 1959, 1960), M. globulus (Kitazawa et al. 2012), and G. maculata (Ubisch 1959) and summarized in Figure 7B. In contrast, it was reported that the larvae of the direct-developing temnopleurid species, H. purpurascens form an amniotic cavity (Morris 1995). These observations strongly suggest that the dependence of adult rudiment formation on the $\mathrm{CM}$ is a common trait among indirect-developing temnopleuroids.

Our previous report indicated that the diameter of the $\mathrm{CM}$ of $M$. globulus gradually increases from approximately 20 to $50 \mu \mathrm{m}$ (between $37.5 \mathrm{~h}$ and 7 days after fertilization at $24^{\circ} \mathrm{C}$ ) until it becomes attached to the hydrocoel (Kitazawa et al. 2012). Conversely, the diameter of the CM of $T$. toreumaticus increased stepwise according to the growth of the larval body. After growth of the CM during the early four-armed larval stage (approximately 13 to $24 \mu \mathrm{m}$ ), its size was maintained until the six-armed larval stage when it again grew to nearly attach to the hydrocoel (approximately $29 \mu \mathrm{m} 15$ days after fertilization; Figure 3E). The size of the CM of $T$. toreumaticus before attachment to the hydrocoel was smaller than that of the M. globulus even though the larvae of these two species are similar in size (approximately $500 \mu \mathrm{m}$ ). In contrast, the size of the $\mathrm{CM}$ in $T$. reevesii changed markedly over 2 days from approximately $20 \mu \mathrm{m}$ (Figures 5 and $6 \mathrm{~A}$ ) to $80 \mu \mathrm{m}$ (Figure 6B) in the six-armed pluteus larval stage, even though the size of the $\mathrm{CM}$ did not change during the four-armed larval stage (Figure 5; approximately $18 \mu \mathrm{m}$ at $\mathrm{CM}$ formation). These results suggest that there are at least two types of CM growth: stepwise during the four- to sixarmed larval stages and rapid during the six-armed stage. In T. toreumaticus, early growth may occur as a result of the dispersion of cells because the cell number of the CM did not change during this period (Figure 3 ) and later the $\mathrm{CM}$ may grow by cell division. Conversely, the rapid growth of the CM observed in $T$. reevesii may be due to the formation of a thin epithelium (Figure 6A,B).

Larvae of both $T$. toreumaticus and $T$. reevesii formed a 'small process' similar to that observed in the larvae of T. hardwickii (Fukushi 1960) and M. globulus (Kitazawa et al. 2012). This observation suggests that formation of the small process may be necessary for the formation of the adult rudiment from the $\mathrm{CM}$, although its function remains unclear. Interestingly, the small process moved close the larval ectoderm and then changed shape to generate numerous filopodia-like structures in T. toreumaticus, $T$. reevesii, and $M$. globulus, thus reducing the distance between the adult rudiment and the larval ectoderm (the filopodia-like structures can be discerned in Figure 4D,D'). This organ may be important for formation of the opening in the ectoderm in metamorphosis. The small process of $T$. toreumaticus was identified just after the attachment of the CM to the hydrocoel (Figure 2), whereas it was identified after formation of the primary podia in T. reevesii (Figure 6) and M. globulus (Kitazawa et al. 2012), or after the hydrocoel had formed five lobes in T. hardwickii (Fukushi 1960). Analysis of the early development of the small process in T. toreumaticus may help to elucidate its function.

In the development of both $T$. toreumaticus and $T$. reevesii, yellowish-green cells were observed on the larval post-oral and postero-dorsal rods, but not on other rods from the six-armed pluteus larval stage (Figures $2 \mathrm{~L}$, 4, and 6). The number of these cells seemed to increase until metamorphosis. Their function is unclear, but the timing of their appearance and growth suggests they may have functions in metamorphosis and dissolution of the larval rods.

The change to the generation of the adult rudiment of sea urchins from the amniotic cavity is believed to have occurred in many species of Euechinoidea following their evolutionary divergence from the Cidaroidea (Emlet 1988; Olson et al. 1993; Figure 7C). However, it is considered that in Temnopleuridea, dependence on the amniotic cavity has switched to dependence on the $\mathrm{CM}$, particularly in indirect-developing species. This is supported by the phylogeny of the temnopleuroids (Jeffery et al. 2003). Development of the adult rudiment from the CM in the Temnopleuridea may serve to protect this morphogenetic process within the larval body, whereas the amniotic cavity remains open to the exterior during adult rudiment formation. In addition, dependence on the CM extends the time available for development of the adult rudiment, temnopleuroid sea urchins form the CM between the prism stage and the early four-armed pluteus stage, and the CM then attaches to the hydrocoel at the six-armed pluteus stage (Figures 2, 3, 4, 5, 6, and 7B; Fukushi 1959; Ubisch 1959; Kitazawa et al. 2012). By contrast, in common indirect-developing species, such as the model sea urchin, S. purpuratus (Smith et al. 2008) and H. pulcherrimus, the amniotic cavity form later at the six- to eight-armed pluteus stage before the amniotic cavity attaches to the hydrocoel (MacBride 1914; Dan 1957; Okazaki 1975; Ishihara and Noguchi 1996). This suggests that evolution of the adult rudiment formation in Temnopleuridea involved ectodermal modification to form the CM. 


\section{Conclusions}

The development of Temnopleurus toreumaticus and $T$. reevesii to metamorphosis are described for the first time. Both species form two PPCs at the prism stage, bilaterally in $T$. toreumaticus and asymmetrically in $T$. reevesii. The right $\mathrm{PPC}$ then degenerates by the four-armed larval stage. From the prism stage, both species start to form an adult rudiment that depends on CM formation. The growth of the $\mathrm{CM}$ and the timing of elongation of the small process vary among species of Temnopleuridea.

\section{Abbreviations}

CM: cell mass; PPC: primary pore canal; PMC: primary mesenchyme cell; SMC: secondary mesenchyme cell.

\section{Competing interests}

The authors declare that they have no competing interests.

\section{Authors' contributions}

CKi designed the experiment with $A Y$ and carried out the sea urchin sampling with CS, HN, CKo, TB, and AY. CS and HN completed to observe the normal development with CKi, CKo, and TB. CKo obtained DAPI analysis, and CKi finalized the manuscript with AY. All authors read and approved the final manuscript.

\section{Acknowledgements}

We thank Dr. M. Noguchi for providing of algae and students in ou laboratories for sampling and suggestion. We also thank the Department of Fishery in Yamaguchi Prefecture and the Yamaguchi Fisheries Cooperative Association for the permission to collect sea urchins. This work was financially supported in part by the Yamaguchi Univ. Foundation, JSPS KAKENHI Grant Numbers 19770195 and 24770227 and from the Marine Invertebrates Research Institute Foundation to C.K.

\section{Author details}

${ }^{1}$ Biological Institute, Faculty of Education, Yamaguchi University, Yoshida 1677-1, Yamaguchi 753-8513, Japan. ²Department of Applied Molecular Bioscience, Graduate School of Medicine, Yamaguchi University, Yoshida 1677-1, Yamaguchi 753-8512, Japan.

Received: 12 September 2013 Accepted: 20 December 2013 Published: 20 January 2014

\section{References}

Aiyar RG (1935) Early development and metamorphosis of the tropical echinoid Salmacis bicolor, Agassiz. Proc Ind Acad Sci B1(11):714-728

Bessodes N, Haillot E, Duboc V, Rottinger E, Lahaye F, Lepage T (2012) Reciprocal signaling between the ectoderm and a mesendodermal left-right organizer directs left-right determination in the sea urchin embryo. PLoS Genet 8(12): e1003121. doi:10.1371/journal.pgen.1003121

Czihak G (1965) Entwicklungsphysiologische Untersuchungen an Echiniden (Experimentelle Analyse der Coelomentwicklung). Roux Arch Entw Mech 155:709-729

Czihak G (1996) Sea urchin embryology in the sixties. Int J Dev Biol 40:97-101

Dan K (1957) Echinoids. In: Kume M, Dan K (eds) Invertebrate embryology. Bai Fu Kan Press, Tokyo, pp 199-212 [in Japanese]

Emlet RB (1988) Larval form and metamorphosis of a "primitive" sea urchin, Eucidaris thouarsi (Echinodermata: Echinoidea: Cidaroidea), with implications for developmental and phylogenetic studies. Biol Bull 174:4-19

Emlet RB (2000) What is a juvenile sea urchin? A comparative and phylogenetic survey of post-metamorphic juveniles. Zygote 8(Supplement 1):S44-S45

Fukushi T (1959) On the cell mass observed on the left side of the pluteus of the sea urchin, Temnopleurus hardwickii. Bull Mar Biol St Asamushi 9(3):133-135

Fukushi T (1960) The formation of the echinus rudiment and the development of the larval form in the sea urchin, Temnopleurus hardwickii. Bull Mar Biol St Asamushi 10(1):65-72

Giudice G (1986) The sea urchin embryo. Springer, Berlin
Hara Y, Kuraishi R, Uemura I, Katow H (2003) Asymmetric formation and possible function of the primary pore canal in plutei of Temnopleurus hardwicki. Develop Growth Differ 45:295-308

Ishihara K, Noguchi M (1996) Chapter 22 Echinoids. In: Ishihara K (ed) Atlas of animal development. Kyoritusyuppann, Tokyo, pp 191-220 [in Japanese]

Jeffery C, Emlet RB, Littlewood DTJ (2003) Phylogeny and evolution of developmental mode in temnopleurid echinoids. Mol Phyl Evol 28:99-118

Kitazawa C, Kawasaki S, Nishimura H, Nakano M, Yamaguchi T, Yamanaka A (2007) Distribution and habitat preferences of sea urchin species in Shirikawa Bay, Yamaguchi, during the period from 2005 to 2007. Bull Fac Edu Yamaguchi Univ 57(2):95-105

Kitazawa C, Nishimura H, Yamaguchi T, Nakano M, Yamanaka A (2009) Novelmorphological traits in the early developmental stages of Temnopleurus toreumaticus. Biol Bull 217(3):215-221

Kitazawa C, Tsuchihashi Y, Egusa Y, Genda T, Yamanaka A (2010) Morphogenesis during early development in four Temnopleuridae sea urchins. Information 13(3B):1075-1089

Kitazawa C, Kobayashi C, Kasahara M, Takuwa Y, Yamanaka A (2012) Morphogenesis of adult traits during the early development of Mespilia globulus Linnaeus, 1758. Zool Stud 51(8):1481-1489

Kroh A, Smith AB (2010) The phylogeny and classification of post-Palaezoic echinoids. J Syst Palaeontol 8(2):147-212

Luo YJ, Su YH (2012) Opposing nodal and BMP signals regulate left-right asymmetry in the sea urchin larva. PLoS Biol 10(10):e1001402. doi:10.1371/ journal.pbio.1001402

MacBride EW (1911) Two abnormal plutei of Echinus and the light which they throw on the factors in the normal development of Echinus. Quart Jour Microsc Sci 57(2):235-250

MacBride EW (1914) Text-book of embryology, vol. I. Invertebrata. Macmillian and Co, London, pp 504-529

MacBride EW (1918) The artificial production of echinoderm larvae with two water-vascular systems, and also of larvae devoid of water-vascular system. Proc Roy Soc Ser B 90:323-348

Morris VB (1995) Apluteal development of the sea urchin Holopneustes purpurescens Agassiz (Echinodermata: Echinoidea: Euechinoidea). Zool J Linnean Soc 114(4):349-364

Mortensen TH (1921) Studies of development and larval forms of echinoderms. G. E. C, GAD, Copenhagen

Nishimura S (1995) Guide to seashore animals of Japan with color pictures and keys, vol II. Hoikusha Publishing co, Ltd, Osaka [in Japanese]

Okada K, Miyauchi H (1958) Figures of the standard early development of Temnopleurus toreumaticus. J Gakugei Bull Tokushima Univ 8:59-71 [in Japanese]

Okazaki K (1975) 7.Normal development to metamorphosis. In: Czihak G (ed) The sea urchin embryo. Springer, Berlin, pp 177-232

Olson RR, Cameron JL, Young CM (1993) Larval development (with observations on spawning) of the pencil urchin Phyllacanthus imperialis: a new intermediate larval form? Biol Bull 185:77-85

Onoda K (1936) 20.Notes on the development of some Japanese echinoids with special reference to the structure of the larval body. Jap J Zool 6(4):637-654

Parks AL, Bisgrove BW, Wray GA, Raff RA (1989) Direct development in the sea urchin Phyllacanthus parvispinus (Cidaroidea): phylogenetic history and functional modification. Biol Bull 177:96-109

Runström J (1912) Quelques observations sur la variation et la correlation cheq la larvae de l'oursin. Bull Inst Oceanogr Monaco 247:1-16

Runström J (1918) AnalytischeStudienüber die Seeigelentwicklung. IV. Roux Arch Entw 43:409-431

Shigei M (1986) The sea urchins of Sagami bay. Maruzen Co., Ltd., Tokyo

Smith AB (1984) Echinoid palaeobiology. Allen \& Unwin, London

Smith MM, Smith LC, Cameron RA, Urry LA (2008) The larval stages of the sea urchin, Strongylocentrotus purpuratus. J Morph 269:713-733

Takata H, Kominami T (2004) Behavior of pigment cells closely correlates the manner of gastrulation in sea urchin embryos. ZoolSci 21(10):1025-1035

Ubisch L (1959) Die Entwicklung von Genocidarismaculata und Sphaerechinus granularis, sowie Bastarde und Merogone von Genocidaris. Pubbl Staz Zool Napoli 31:159-208

Wray GA, Kitazawa C, Miner B (2004) Chapter 4. Culture of echinoderm larvae through metamorphosis. Meth Cell Biol 2004(74):75-86

doi:10.1186/1810-522X-53-3

Cite this article as: Kitazawa et al:: Development of the sea urchins Temnopleurus toreumaticus Leske, 1778 and Temnopleurus reevesii Gray, 1855 (Camarodonta: Temnopleuridae). Zoological Studies 2014 53:3. 